\title{
Satisfação dos usuários do aplicativo de compra on-line da Rede Pontual Supermercados
}

\author{
Eduardo Júnio de Araújo $^{1}$ \\ Edson Arlindo Silva ${ }^{2}$ \\ Rafaella Dutra Goulart
}

\begin{abstract}
Resumo: Nos últimos anos, as novas tecnologias ocupam cada vez mais espaço em nosso meio e têm facilitado o trabalho no dia a dia das empresas (ALVES, 2009; GONÇALVES, 2007). Cientes dessa realidade, muitos estabelecimentos buscaram conciliar os benefícios resultantes da utilização de softwares à necessidade de atrair $\mathrm{e}$ fidelizar clientes. Nesse sentido, esta pesquisa tem o objetivo de identificar os principais fatores geradores de satisfação com o uso do aplicativo de compra on-line da rede Pontual Supermercados, localizada no município de Ituiutaba, estado de Minas Gerais. O método utilizado foi o estudo de caso (BARDIN, 2010; VERGARA, 2015; YIN, 2005), com análise descritiva e interpretativa de conteúdo, e o instrumento de coleta de dados um questionário (survey). Os resultados do diagnóstico realizado entre usuários do aplicativo Pontual mostram que fatores como comodidade, rapidez, economia de tempo, promoções, preços e bonificações interferem na satisfação e contribuem significativamente para a fidelização de usuários/clientes, conforme demonstram os estudos de Alberto (2009), Gonçalves (2007) e Lima (2001). A presente pesquisa pode concorrer para ampliar o debate sobre o tema, bem como auxiliar a rede Pontual Supermercados e outras organizações do mesmo ramo de atividade na tomada de decisões e na escolha de um método (aplicativo de compra on-line) que, além de atrair clientes, reduz custos, concorre para a racionalização de processos (como a redução de panfletos e materiais impressos, por exemplo) e, consequentemente para a responsabilidade socioambiental.
\end{abstract}

Palavras-chave: Satisfação. Aplicativo de compra. Consumidor. Setor supermercadista.

\section{Users satisfaction for the Pontual supermarket chain online shopping appilcation}

Abstract: In the recent years, new technologies have been gaining more space over our environment, thus, it has been facilitating and helping enterprises on a daily basis (ALVES, 2009; GONÇALVES, 20007). Aware of this reality, supermarket Pontual Chain aimed to conciliate these characteristics to the need to attract and captivate its clients. In this direction, a research was conducted at supermarket Pontual Chain, situated in Ituiutaba city in the state of Minas Gerais aiming to identify the main generator factors of satisfaction with the use of an online shopping application at supermarket Pontual Chain, being this the main goal of this present study. The methodology was concentrated on the diagnosis reported through users' satisfaction descriptive and interpretative survey analysis of content, emphasizing the case study method (BARDIN, 2010; VERGARA, 2015; YIN, 2005). The results show that there is indeed a number of factors as comfort, speed, time saving, sales, prices and benefits that interfere with the satisfaction of users-clients and contribute mainly to promote clients' loyalty, as the results revealed by the studies of Alberto (2009), Gonçalves (2007) e Lima (2001). Ultimately, it is considered that this study can contribute to broaden the debate and reflections on the approached theme and also to the studied

\footnotetext{
1 Graduando em Administração pela Universidade Federal de Uberlândia - Campus Pontal (Ituiutaba-MG). E-mail: eduardo_junioaraujo@hotmail.com.

2 Pós-Doutor em Administração pela Universidade de São Paulo (USP). Pesquisador e Professor da Universidade Federal de Uberlândia - Campus Pontal (Ituiutaba-MG). Membro do Núcleo de Estudos e Pesquisa em Administração e Ciências Contábeis (NEPACC/CNPq/UFU). Consultor Ad hoc e Pesquisador-Bolsista de Produtividade do CNPq. Professor Permanente do Programa de Pós-Graduação em Gestão Organizacional da Universidade Federal de Catalão (UFCAT). Email: edsonasilva@ufu.br.

3 Bacharela em Administração pela Universidade Federal de Uberlândia - Campus Pontal. E-mail: afaelladutragoulart@hotmail.com.
} 
company, since it may assist in present and future decision making, support enterprises that share the same segment of the market help them choose a method (online shopping application) that will attract clients, reduce costs and help with the notion of Social and Environmental Responsibility process such as reduction of leaflets distribution and printed material.

Keywords: Satisfaction. Shopping application. Consumer. Supermarket sector.

\section{Introdução}

Com os avanços tecnológicos, os meios de comunicação também foram marcados por mudanças e progressos e essa nova conjuntura exige das pessoas capacidade de adaptação. No mundo dos negócios, tais mudanças estão mais presentes e são indispensáveis, visto que as empresas, por serem competitivas, têm a necessidade de comunicar-se de maneira eficaz com clientes, para transmitir informações que auxiliem na otimização dos negócios e aumentem a eficiência dos produtos e/ou serviços oferecidos, sempre com o objetivo de facilitar para ambas as partes.

De acordo com os estudos de Samara (2015), entre os meios de comunicação mais rápidos e eficientes, destaca-se a internet, tanto pela possibilidade de troca de mensagens e de informações quanto pelo tamanho do alcance da rede. Para as empresas de maneira geral, a internet movimenta e facilita o trabalho no setor empresarial. Por meio dela, ampliam-se as oportunidades de expansão de mercados. É com base nesse contexto de mudanças tecnológicas e inovadoras que se pretendeu analisar a satisfação de clientes que utilizam o aplicativo de compras on-line da rede Pontual Supermercados, situada na cidade de Ituiutaba, estado de Minas Gerais.

A unidade de análise escolhida, a rede Pontual Supermercados, atua no mercado há mais de 31 anos e é formada por cinco lojas, um posto de combustíveis e cerca de 319 funcionários. Suas lojas também dispõem de prestação de serviços, como lotéricas, lanchonetes, restaurantes e caixas eletrônicos da rede Banco 24 horas. A rede Pontual possui site oficial, páginas no Facebook e Instagram, todos de caráter informativo. Além disso, aderiu ao aplicativo de delivery "Tonolucro", por meio do qual disponibiliza alguns itens de seu estoque aos consumidores. A rede também criou e ofereceu aos seus clientes um aplicativo denominado "Pontual Supermercados Ituiutaba".

Segundo a Associação Brasileira de Supermercados (ABRAS, 2019), o segmento supermercadista brasileiro conta atualmente com 89,7 mil lojas, ocupando uma média de 22,2 milhões de metros quadrados de área de vendas e empregando 1.853.122 funcionários. Esses dados são provenientes de uma pesquisa realizada com 944 empresas, das quais, as 500 maiores empregam grande parte dos funcionários alocados no setor varejista. Estimase que somente esse setor possua 656.186 mil funcionários.

Nesta pesquisa, a análise concentrou-se no segmento supermercadista, considerando aspectos como a expansão dos supermercados e hipermercados em Ituiutaba, a extensa variedade de opções para os consumidores e o consequente aumento da concorrência no município.

Um estudo de Souza e Magrini (2017), denominado "Produção do espaço e consumo: um estudo a partir da atividade supermercadista em Ituiutaba-MG", mostrou que, conforme dados do Sindicato do Comércio Varejista de Ituiutaba, a cidade possuía 70 estabelecimentos cadastrados em 2017. Destes, 52 consideram a atividade principal de minimercado/mercearia/armazém, 15 integram o grupo de supermercados e três incluem-se em atividades distintas dos anteriores. 
Nesse contexto, a presente pesquisa procurou responder à seguinte pergunta: Quais fatores são determinantes para gerar a satisfação de clientes que utilizam o aplicativo de compra on-line desenvolvido pela rede Pontual Supermercados? O objetivo principal é identificar os principais fatores de influência na satisfação dos consumidores quanto à prestação de serviços e aos produtos ofertados pela rede Pontual Supermercados. Especificamente, o propósito é: i) descrever os motivos que levam determinados clientes a usar o aplicativo desenvolvido pela rede Pontual; ii) identificar de que maneira um software interfere na satisfação de clientes de uma rede supermercadista; iii) verificar se o aplicativo em questão contribui para a fidelização de clientes.

Levando-se em conta o contexto ainda em curso da Pandemia de Covid-19, este trabalho justifica-se, uma vez que, devido à necessidade de se cumprir as medidas sanitárias preventivas para evitar a contaminação das pessoas, o segmento supermercadista passou a ser o mais fiscalizado, tanto pelos órgãos oficiais quanto pelos consumidores, que evitam sair de casa ou procuram reduzir o tempo de permanência no supermercado. Assim, o aplicativo Pontual Supermercados, tema deste estudo, torna-se ferramenta importante para facilitar as tarefas diárias e auxiliar no cuidado com a saúde.

De acordo com o Decreto Municipal n 9.363, de 20 de março de 2020, aos supermercados de Ituiutaba foram determinadas, entre outras, as seguintes medidas:

Organizem a entrada e saída de seus estabelecimentos, através de senhas (descartáveis) e controle de entrada por quantidade a ser definida por metro quadrado disponível para circulação de pessoas na área interna do estabelecimento; (...) $\mathrm{Na}$ entrada ao supermercado seja permitida somente uma pessoa por carrinho; Os supermercados devem se adequar e priorizar as vendas por canais de comunicação e tecnologias diversas, inclusive com sistema de tele entrega (PREFEITURA DE ITUIUTABA, 2020).

Assim, o objetivo do referido Decreto é, por meio de um processo transparente e de normas bem estabelecidas, trazer mais segurança aos clientes, manter as vendas e preservar vidas.

Desse modo, é importante ressaltar, o atendimento que proporciona a satisfação do cliente é essencial a qualquer empresa. No entanto, diante de fatores como aumento da competitividade no setor supermercadista local, expansão da globalização, prolongamento (e agravamento) da crise econômica diante da Pandemia de Covid19 e necessidade de redução de custos, as organizações devem encontrar vias que facilitem o bom relacionamento entre cliente e empresa. Nesse sentido, este trabalho buscou identificar o grau de satisfação de clientes diante de inovações tecnológicas, bem como se o aplicativo desenvolvido pela rede Pontual tem promovido, efetivamente, a fidelização esperada.

\section{Referencial teórico}

Para uma melhor compreensão do tema proposto neste estudo, apresentam-se a seguir conceitos relacionados ao assunto (como modelos de satisfação, por exemplo) e uma discussão sobre práticas de gestão comumente verificadas em empresas do setor supermercadista.

\subsection{Satisfação do consumidor}

Lima (2001) assevera que o maior desafio dos profissionais de marketing atualmente é atender às demandas (bastante rígidas) de satisfação do cliente. Essa ideia complementa os estudos de Révillion (1998), 
segundo os quais, os consumidores têm altos níveis de exigência por bens e serviços que venham a adquirir. Ainda de acordo com Lima (2001), a satisfação abarca as seguintes perspectivas: individual, empresarial, mercado e sociedade. A primeira perspectiva diz respeito a um propósito individual, que é a busca de satisfação no consumo de bens e serviços. A segunda traz a visão das empresas que, na maioria das vezes, têm por objetivo principal o lucro, alcançado com a venda de produtos e serviços. Cabe-lhes, portanto, satisfazer as expectativas do cliente e colocar em prática o quesito "fidelização", visto que a insatisfação ocasiona uma resposta negativa ao comércio. A terceira perspectiva abrange o mercado, em que se analisa a influência na regulamentação das políticas que o regem, independentemente da natureza do setor, seja público, seja privado. A quarta e última perspectiva recai sobre a sociedade, sendo, portanto, amplamente abrangente, porque consegue distinguir o consumidor não apenas da forma sob a qual ele se apresenta, ou seja, um mero comprador, mas também como alguém que se preocupa em manter a saúde mental, física e financeira.

Para atender a essas perspectivas, o varejo passa por um processo de melhoria contínua, já que a satisfação do consumidor está intimamente relacionada à qualidade daquilo que se adquire, sendo, desse modo, capaz de levar a organização ao sucesso (SILVA, 2009). Alves e Goedert (2009) asseveram que a atuação dos funcionários exerce impacto direto sobre o desempenho das empresas. Para os autores, é de extrema importância que os empregados conheçam os produtos e serviços oferecidos, porque são eles que têm contato direto com os clientes por meio da exposição/venda e sabem qual a melhor estratégia a ser seguida para atingi-los. Nesse contexto constata-se que, ao longo dos anos, o mundo tem sido palco de constantes mudanças, incertezas e perplexidades, em que se percebe uma mudança, da sociedade industrial para a sociedade da informação (HAAK, 1998).

O conjunto de desafios e oportunidades vivenciados pelas organizações é, cada vez mais, complexo devido a aspectos como multiplicidade de demandas, novos ambientes de trabalho, competitividade sempre crescente e exigências do mercado. Tal condição lhes impõe buscar alternativas para sobreviver e continuar as atividades (MANGONI, 2008). Trata-se, portanto, de um processo de reformulação constante em que se deve procurar instrumentos para garantir a produtividade e a melhoria da qualidade de produtos e serviços.

Os instrumentos referentes à qualidade e à produtividade também devem estar voltados para a satisfação das necessidades de clientes e colaboradores, visto que o talento humano passou a ser um traço diferencial no sucesso das organizações (MANGONI, 2008). Estudos anteriores, como a pesquisa de Campos (1992), por exemplo, constataram:

\footnotetext{
A insatisfação é um estado natural do ser humano. O ser humano fica satisfeito em situações momentâneas, retornando sempre ao seu estado natural que é a insatisfação. Se um ser humano convive com um grupo de pessoas que tem suas necessidades básicas atendidas ele desfrutará do estado de satisfação mais frequentemente e o grupo de pessoas estará num "estado de saúde mental” ou "elevado moral” (CAMPOS, 1992, p. 151).
}

Diante dessa realidade, as organizações precisam desenvolver métodos que proporcionem um ambiente favorável para colaboradores e clientes, com o objetivo não só de maximizar o desempenho daqueles, mas também de gerar a satisfação destes, haja vista que os indivíduos têm influência direta no grau de produtividade, na qualidade de um serviço/produto e, principalmente, na lucratividade. Por isso, no âmbito das organizações é, cada vez mais, notória a preocupação com o desenvolvimento de práticas administrativas que tendem a promover os 
fatores de satisfação, seja na relação com o cliente, seja na relação com os colaboradores, os quais têm papel relevante no ambiente organizacional e na prosperidade da empresa.

Sendo assim, nesta pesquisa, priorizou-se o segmento supermercadista, com um estudo específico sobre a rede Pontual Supermercados, para mostrar como a satisfação de clientes e colaboradores é determinante para a sobrevivência desse setor, constituindo, portanto, um dos pilares que levam à fidelização de clientes, um assunto que será discutido a seguir.

\subsection{Fidelização de clientes}

Conforme se afirmou no último parágrafo da seção anterior, a fidelização de clientes é um dos pontoschave para a manutenção das atividades de uma empresa. Um cliente satisfeito busca novamente pelo produto/serviço. Gonçalves (2007) reforça essa ideia e assevera que a fidelidade é um comportamento difícil de se entender em qualquer tipo de relação. Na opinião do autor, fidelização significa validar uma escolha, ou seja, durante algum tempo se permanece com determinada opção. Alberto (2011) complementa a visão de Gonçalves (2007) e diz que a fidelização constitui um comportamento perceptível, em que há uma alta demanda por determinados produtos/serviços. Trata-se de um processo baseado na repetição da compra, em que se notam atitudes que explicam a relação e o contato do consumidor com a empresa. A fidelização concretizar-se-ia, por exemplo, na opção pelas compras em determinada empresa, em vez das concorrentes, nos bons comentários dos clientes entre os seus pares.

Ao considerar que o consumidor fiel está intimamente ligado à empresa, Gonçalves (2007) defende a ideia de que se deve a todo o momento valorizar o cliente, pois, nesse caso, o esforço é menor e a liberdade dada a este aumenta o poder na hora das compras. Ademais, clientes com altos níveis de satisfação podem se tornar fidedignos e, com isso, passam a não se importar tanto com preços, e sim com a forma como são tratados. Com base nesse contexto, a seção a seguir mostra as características do segmento de supermercados, permitindo compreender a importância desse comércio, considerado necessário para a economia nacional, bem como de que maneira as categorias satisfação e fidelização se manifestam no dia a dia do setor.

\subsection{Caraterização do segmento supermercadista no Brasil}

Os supermercados são grandes estabelecimentos onde se comercializam produtos e serviços. Com o passar do tempo, tornaram-se essenciais na vida dos consumidores, visto que disponibilizam alimentos, produtos de limpeza, higiene pessoal e um portfólio com diferentes opções de artigos e marcas, tudo isso para atrair o consumidor final aos seus ambientes internos (LIMA, 2001). Para Alves e Goedert (2009), uma vez que o cliente está, cada vez mais, exigente, surge a necessidade de otimização de produtos e serviços, em que o ponto central é o atendimento ágil e de qualidade. Desse modo, os produtos e processos de atendimento devem estar totalmente voltados ao cliente alvo. Com base nessa relação entre supermercado e consumidor/cliente, é importante fazer a seguinte observação:

A importância do supermercado pode ser destacada por ter sido um dos primeiros formatos varejistas a estudar a disposição das mercadorias na loja, bem como o movimento dos consumidores em seu interior. Além disso, o supermercado procura 
atrair a preferência do consumidor por meio de uma maior velocidade nos check-outs $e$ layouts bem estudados (LIMA, 2001, p. 9).

Diante do exposto, pode-se observar que o check out de supermercado ideal é uma exigência do consumidor final, um fator de interesse para gerar fidelização entre o cliente e a rede Pontual. Outro ponto a ser destacado são os layouts. Segundo Lima (2001), referem-se à exposição e às ofertas de produtos/serviços. Considerados de grande relevância, requerem boas estratégias e noções de planejamento.

Os varejistas do setor supermercadista têm tido um grande desafio em comum nos últimos anos: fidelizar seus consumidores e elevar suas vendas. No entanto o cenário econômico tem se mostrado um obstáculo para que alcancem esse objetivo, com o shopper perdendo poder de compra e com a dificuldade em conseguir crédito. Para muitos, a solução encontrada para driblar o problema foi o cartão private label, ou cartão de loja, como é mais conhecido (ABRAS, 2019, p. 4).

De acordo com Révillion (1998), um dos mais importantes serviços de um supermercado deve ser a facilidade e a disposição para fazer um cartão de crédito personalizado (com logomarca do estabelecimento) para seus clientes. Esse procedimento, muito usual em redes de supermercados do Brasil, objetiva estimular as vendas e estreitar os laços com os clientes.

\section{Metodologia da pesquisa}

O ponto de partida para o pesquisador iniciar um estudo é a definição do objetivo e da abordagem (qualitativa, quantitativa ou a mescla de ambas) a ser adotada. Nesse sentido, Godoy (2006) e Gil (2007) classificam as pesquisas sociais da seguinte forma: descritivas, explicativas e exploratórias. Nesta pesquisa, priorizou-se a perspectiva descritiva, a qual, segundo Vergara (2015), permite identificar as características de determinada população (ou organização ou fenômeno) a ser investigada. Possibilita também estabelecer correlações entre variáveis e definir sua natureza. A pesquisa descritiva não tem compromisso em explicar os fenômenos, embora sirva de base para tal, de maneira que, nesse tipo de investigação, os pesquisadores têm preocupação prática, como acontece com a pesquisa exploratória (VERGARA, 2015).

Para que o objetivo deste trabalho fosse alcançado, adotou-se uma pesquisa de natureza qualitativa, ou seja, foram feitas análises de conteúdos e uma interpretação crítica de informações/dados coletados por meio do método survey, e empregou-se o estudo de caso na rede Pontual Supermercados como estratégia predominante. De acordo com Yin (2005), a preferência pelo estudo de caso deve ocorrer quando é possível fazer observações diretas e entrevistas sistemáticas em uma unidade que permita uma análise mais profunda. Tal abordagem visa ainda ao exame detalhado de um ambiente, de um simples sujeito ou de uma situação em particular, de modo a permitir seu amplo conhecimento (VERGARA 2015; GIL, 2007; GODOY, 2006). Considerando a possibilidade de realizar observações diretas em determinada organização (supermercado), hipoteticamente, de alta competitividade no mercado, optou-se por esse método como estratégia de pesquisa.

Com base nesse contexto, o presente trabalho empregou a observação participante, valendo-se do fato de o pesquisador ser colaborador efetivo da rede Pontual Supermercados. Segundo Roesch (2005), para aplicar essa técnica é preciso vivenciar o cotidiano da unidade de análise e ter acesso às informações necessárias à pesquisa acadêmico-científica. Em linhas gerais, a observação participante foi importante e ofereceu vantagens, como: 
informações sobre o comportamento dos clientes que utilizam o aplicativo rede Pontual; compreensão da situação investigada; oportunidade de verificar o fenômeno de maneira natural; estrutura estabelecida; flexibilidade.

Dentro da perspectiva apresentada, o questionário (survey) tornou-se uma das principais fontes para a coleta dos dados/informações. Baseado na escala Likert (organizada na forma de respostas objetivas/diretas), foi aplicado entre os colaboradores e clientes que utilizam o aplicativo de compra on-line da rede Pontual Supermercados, localizada no município de Ituiutaba, estado de Minas Gerais.

Os dados/informações foram organizados, analisados, codificados e categorizados por meio do emprego da técnica de análise de conteúdo (BARDIN, 2010), cuja ênfase recai no conteúdo manifesto do discurso e nos argumentos apresentados. Entre outras diferentes técnicas, trata-se de formas de interpretar o conteúdo de um texto ou entrevista/questionário. $\mathrm{O}$ anonimato dos respondentes foi garantido.

O público-alvo estimado no início da presente pesquisa era de 7.200 clientes, considerando todos aqueles que baixaram o aplicativo de compra on-line da Rede Pontual Supermercados. No entanto, devido ao curto espaço de tempo para a realização deste estudo, foi possível contatar 385 usuários, sendo que apenas 120 aceitaram responder ao questionário de pesquisa (survey). A análise e discussão das respostas obtidas, bem como mais informações e dados associados à temática presente estão expostos na seção a seguir.

\section{Resultados da pesquisa}

A pesquisa realizada durante a execução deste trabalho teve como objetivo principal identificar os principais fatores geradores de satisfação com o uso do aplicativo de compra on-line na prestação de serviços e produtos ofertados pela rede Pontual Supermercados. Presente na cidade de Ituiutaba-MG há mais de 31 anos, a empresa iniciou suas atividades no mês de julho do ano de 1989. Atualmente, conta com cinco lojas e um posto de combustíveis, distribuídos nos bairros Ipiranga, Platina, Junqueira, Natal e Canaã. Responsável por gerar cerca de 319 empregos diretos, possui significativa influência nas economias local e regional, já que atrai clientes de municípios próximos à Ituiutaba, como Capinópolis, Cachoeira Dourada de Minas, Gurinhatã, Canápolis, Ipiaçu, Santa Vitória e Campina Verde.

Os resultados obtidos por meio desta pesquisa servirão de apoio para tomadas de decisões pelos diretores e gerentes da rede Pontual. Poderão também auxiliar futuras pesquisas do segmento supermercadista e comércio em geral. Sendo assim, para um melhor entendimento e visualização dos resultados, a seguir são apresentados gráficos e tabelas e feitas algumas reflexões acerca da relação entre as perguntas contidas no questionário (foco nos clientes) e os relatos obtidos com a aplicação da técnica de observação participante.

\subsection{Caracterização da rede Pontual Supermercados}

A rede Pontual Supermercados originou-se em 1965 com o armazém União, de propriedade dos irmãos Ênio, Hélio e Joaquim. Na década de 1980, os empresários acresceram sua participação no comércio de Ituiutaba com três estabelecimentos do setor supermercadista. No ano de 1989, os três sócios proprietários da rede Pontual decidiram reorganizar a sociedade, bem como planejar a sua expansão.

Em 1998, o prédio onde tudo começou ampliou-se (passou a ter $340 \mathrm{~m}^{2}$ ) e o nome de origem mudou-se para o nome fantasia "supermercado Pontual". No início do século XXI, a empresa começou a expandir suas 
instalações, bem como o número de lojas na cidade de Ituiutaba. Contando com uma média de 45 funcionários, a área de vendas passou a ocupar $1400 \mathrm{~m}^{2}$ e a oferecer novidades aos clientes, como: padaria, açougue, lanchonete, produtos de hortifrutigranjeiros e um amplo estacionamento.

No ano de 2001, adquiriu-se a segunda loja, localizada no bairro Ipiranga. O novo espaço contava com 80 $\mathrm{m}^{2}$ e cinco colaboradores. Com boas perspectivas, nesse mesmo ano, se iniciou a ampliação dessa unidade. Em 2005, a empresa inaugurou a sua terceira loja, localizada no bairro Junqueira, com área de vendas de mais de 600 $\mathrm{m}^{2}$ e 35 empregos diretos. Com esse crescimento constante, o empreendimento ganhou o status de rede Pontual Supermercados. Ainda em 2005, dia 02 de julho, inaugurou-se a ampliação da segunda loja. Considerada um dos maiores investimentos no setor supermercadista da região, a rede passou a ter $2.300 \mathrm{~m}^{2}$ e a participação média de 115 colaboradores diretos, oferecendo aos clientes, além dos serviços citados anteriormente, um restaurante com ambiente climatizado e estacionamento.

Três anos após a sua inauguração, amplia-se a primeira loja da unidade da Rede Pontual (localizada no bairro Platina). O espaço passa de $240 \mathrm{~m}^{2}$ para $4.080 \mathrm{~m}^{2}$ de área construída, e o número de funcionários, de oito para 135. No ano de 2010, inicia-se a abertura de mais uma loja, a quarta da rede Pontual, localizada no bairro Natal, com cerca de 30 colaboradores. Oito anos depois, em 2018, outra conquista, uma loja no bairro Canaã, com mais de 32 empregos diretos. A rede não parou de crescer e, em 20 de agosto do ano de 2019, resolveu diversificar seu portfólio com a inauguração do primeiro posto de combustíveis em um espaço anexo da loja do bairro Ipiranga. Atualmente, conforme se citou, a empresa conta com cinco lojas, um posto de combustíveis e gera cerca de 319 empregos diretos. Assim, a rede Pontual vem aumentando consideravelmente a sua competividade, enfrentando a concorrência (sempre crescente) e se posicionando estrategicamente na região de Ituiutaba.

\section{2 Perfil da amostra dos clientes da rede Pontual Supermercados}

O questionário foi respondido por 120 clientes usuários do aplicativo de compra on-line, os quais possuem cadastro formal na rede Pontual Supermercados. A maior parte dos respondentes é composta de mulheres, e corresponde a 55,83\% da amostra. Os homens representam 44,17\% do total.

A média de idade da maioria dos informantes (considerando homens e mulheres) é de 20 a 30 anos, totalizando 58,33\% da amostra. Esse resultado mostra a facilidade e a vocação natural dos mais jovens para novas tecnologias. Outros 22,5\% dos participantes estão na faixa etária de 31 a 40 anos, 12,5\%, de 41 a 50 anos e 6,67\% acima de 51 anos de idade.

No que diz respeito aos rendimentos mensais dos respondentes, 25,83\% têm rendimentos abaixo de $\mathrm{R} \$$ $1.000,00,45 \%$ recebem de $\mathrm{R} \$ 1.000,01$ a $\mathrm{R} \$ 2.000,00,14,17 \%$ de $\mathrm{R} \$ 2.000,01$ a $\mathrm{R} \$ 3.000,00$ e $15 \%$ acima de $\mathrm{R} \$$ 3.000,00 por mês. Esses números mostram que a maioria da clientela da rede Pontual Supermercados pertence às classes D e E, de acordo com a classificação do Instituto Brasileiro de Geografia e Estatística (IBGE, 2020).

Com base no perfil sociodemográfico dos participantes da pesquisa, foi possível verificar a frequência de compras na rede Pontual Supermercados. Entre os respondentes, 16,67\% fazem compras diariamente, 23,33\% de duas a três vezes na semana, 25,83\% semanalmente, 15,83\% quinzenalmente e 18,33\% mensalmente. 


\subsection{Análise e discussão dos resultados}

Após análise do perfil sociodemográfico dos clientes, optou-se por avaliar a satisfação dos usuários em relação ao aplicativo Pontual (tema deste estudo), por meio do questionário, adaptado em escala Likert, e aplicado entre os clientes, via plataforma survey, pelo método de web link WhatsApp, conforme o banco de dados repassado pela rede Pontual Supermercados.

As respostas sobre os fatores que interferem na escolha da rede Pontual Supermercados estão destacadas na tabela 1:

Tabela 1 - Fatores que Interferem na Escolha da Rede Pontual Supermercados

\begin{tabular}{|c|c|c|c|c|c|}
\hline $\begin{array}{c}\text { ASPECTOS } \\
\text { ABORDADOS }\end{array}$ & $\begin{array}{l}\text { 5-Muito } \\
\text { satisfeito }\end{array}$ & $\begin{array}{c}\text { 4- } \\
\text { Satisfeito }\end{array}$ & $\begin{array}{c}\text { 3- } \\
\text { Indiferente }\end{array}$ & $\begin{array}{l}\text { 2-Pouco } \\
\text { satisfeito }\end{array}$ & $\begin{array}{c}1- \\
\text { Insatisfeito }\end{array}$ \\
\hline Atendimento prestado & $34,17 \%$ & $53,33 \%$ & $5,83 \%$ & $5,83 \%$ & $0,83 \%$ \\
\hline Formas de pagamento & $40,83 \%$ & $50,83 \%$ & $7,50 \%$ & $0,83 \%$ & $0,00 \%$ \\
\hline Aplicativo da rede & $24,17 \%$ & $50,83 \%$ & $16,67 \%$ & $5,00 \%$ & $3,33 \%$ \\
\hline Disponibilidade de produtos & $21,67 \%$ & $55,83 \%$ & $14,17 \%$ & $7,50 \%$ & $0,83 \%$ \\
\hline Preços & $9,17 \%$ & $39,17 \%$ & $19,17 \%$ & $20,00 \%$ & $12,50 \%$ \\
\hline Marcas & $20,00 \%$ & $56,67 \%$ & $15,83 \%$ & $7,50 \%$ & $0,00 \%$ \\
\hline Localização & $45,83 \%$ & $49,17 \%$ & $3,33 \%$ & $1,67 \%$ & $0,00 \%$ \\
\hline Entrega em domicílio & $35,00 \%$ & $40,83 \%$ & $19,17 \%$ & $3,33 \%$ & $1,67 \%$ \\
\hline Pedidos pelo WhatsApp & $20,83 \%$ & $39,17 \%$ & $36,67 \%$ & $1,67 \%$ & $1,67 \%$ \\
\hline $\begin{array}{l}\text { Pedidos pelo telefone com } \\
\text { atendente }\end{array}$ & $21,67 \%$ & $38,33 \%$ & $37,50 \%$ & $1,67 \%$ & $0,83 \%$ \\
\hline $\begin{array}{c}\text { Pedidos pelo supermercado } \\
\text { virtual }\end{array}$ & $21,67 \%$ & $45,00 \%$ & $27,50 \%$ & $2,50 \%$ & $3,33 \%$ \\
\hline
\end{tabular}

Fonte: Resultados da Pesquisa, 2020.

Em conjunto com a Tabela 1, os resultados apresentados na Tabela 2 (abaixo) revelam que a maioria dos clientes está muito satisfeito ou satisfeito em relação aos fatores apresentados, mas existem aqueles que não se manifestaram diante de alguns desses fatores. Os resultados mais significativos referem-se aos pedidos realizados por meio do WhatsApp, pelo telefone e pelo supermercado virtual. Nesse quesito, parte dos respondentes se manifestou como "indiferente". Uma justificativa para tal reação pode ser o fato de optarem por não utilizar o método de fazer compras por pedidos e preferirem o contato direto com a loja física. Outro ponto que chama atenção é em relação aos preços, já que 10,83\% se manifestaram como pouco satisfeitos e 12,5\%, insatisfeitos. Tendo em vista a disponibilidade de produtos e as marcas disponíveis pela rede, é possível observar uma pequena interferência também entre os respondentes, ou seja, é um ponto a ser estudado e melhorado. Também foram 
abordadas no questionário perguntas relacionadas à satisfação dos clientes em relação ao uso do aplicativo Pontual.

Tabela 2 - Fatores que levaram os clientes a instalar o APP estudado

\begin{tabular}{|c|c|c|c|c|c|}
\hline & $\begin{array}{l}\text { 5- Muito } \\
\text { satisfeito }\end{array}$ & 4- Satisfeito & 3- Indiferente & 2- Pouco satisfeito & 1- Insatisfeito \\
\hline Preços mais baixos & $15,83 \%$ & $45,83 \%$ & $16,67 \%$ & $10,83 \%$ & $10,83 \%$ \\
\hline $\begin{array}{c}\text { Descontos em diversos } \\
\text { produtos }\end{array}$ & $21,01 \%$ & $49,58 \%$ & $10,08 \%$ & $14,29 \%$ & $5,04 \%$ \\
\hline $\begin{array}{l}\text { Acúmulo de points, } \\
\text { gerando "CASHBACK" } \\
\text { (dinheiro de volta) }\end{array}$ & $23,33 \%$ & $36,67 \%$ & $25,83 \%$ & $9,17 \%$ & $5,00 \%$ \\
\hline Promoções & $20,83 \%$ & $49,17 \%$ & $13,33 \%$ & $13,33 \%$ & $3,33 \%$ \\
\hline $\begin{array}{l}\text { Notificações exclusivas } \\
\text { de ofertas diárias para } \\
\text { clientes do aplicativo }\end{array}$ & $26,05 \%$ & $49,58 \%$ & $14,29 \%$ & $5,88 \%$ & $4,20 \%$ \\
\hline $\begin{array}{c}\text { Facilidade para ver } \\
\text { promoções, jornais de } \\
\text { ofertas e outros }\end{array}$ & $25,00 \%$ & $56,67 \%$ & $14,17 \%$ & $3,33 \%$ & $0,83 \%$ \\
\hline
\end{tabular}

Fonte: Resultados da Pesquisa, 2020.

Pode-se observar que o fator de maior de influência no aplicativo é a facilidade de ver promoções, jornais de ofertas e outros. Entre os usuários, 56,67\% demonstraram estar satisfeitos e 25\% muito satisfeitos. Trata-se de um aspecto que proporciona diferenciais, por um lado, redução dos custos no uso dos panfletos (papéis), por outro, e consequentemente, efetivação da responsabilidade socioambiental da rede Pontual. Outro ponto a ser observado é o desconto pelo cadastro do CPF no aplicativo. Os que estão muito satisfeitos somam 21,01\%, satisfeitos, 49,58\%, indiferentes, 10,08\%, pouco satisfeitos, 14,29\% e insatisfeitos, 5,04\%. Este último é, portanto, um quesito que merece atenção da empresa. Tais resultados vão ao encontro de pontos importantes sobre satisfação e insatisfação de clientes discutidos nos estudos de Alberto (2009), Gonçalves (2007) e Lima (2001). Pensados em contextos distintos, esses aspectos revelam os desafios e as possibilidades de promover a satisfação e corrigir os elementos que colaboram para a insatisfação dos consumidores.

Assim, o acesso mais fácil a informações sobre promoções e ofertas diárias constitui um dos fatores que mais contribuem para a satisfação dos usuários do aplicativo, de forma que 26,05\% se declararam muito satisfeitos, 49,58\%, satisfeitos, 14,29\%, indiferentes, 5,88\%, pouco satisfeitos e 4,20\%, insatisfeitos. O ponto que chamou atenção foi o fato de que 10,83\% dos respondentes estão insatisfeitos em relação aos preços mais baixos. Em contrapartida, 15,83\% estão muito satisfeitos, 45,83\% satisfeitos, e 16,67\% indiferentes quanto ao aspecto preço.

No que se refere às promoções, 20,83\% estão muito satisfeitos, 49,17\% satisfeitos, 13,33\% se declararam indiferentes, 13,33\% pouco satisfeitos e 3,33\% insatisfeitos. O acúmulo de points gerando cashback indicou um total de $25,83 \%$ de indiferentes. Esse percentual pode estar relacionado ao pouco conhecimento dos respondentes sobre o assunto. Por outro lado, mais de 50\% declararam estar satisfeitos ou muito satisfeitos nesse quesito. 
Outra pergunta específica do questionário foi sobre a utilização do aplicativo. O objetivo foi verificar a adaptação dos participantes à operacionalização e ao manuseio do aplicativo, conforme demonstra a tabela 3.

Tabela 3 - Fatores de adaptação ao uso do aplicativo de compra da rede Pontual

\begin{tabular}{llllll}
\multicolumn{1}{c}{$\begin{array}{c}\text { ASPECTOS } \\
\text { ABORDADOS }\end{array}$} & $\begin{array}{l}\text { 5-Discordo } \\
\text { totalmente }\end{array}$ & $\begin{array}{l}\text { 4-Discordo } \\
\text { parcialmente }\end{array}$ & $\begin{array}{l}\text { 3-Não discordo/ } \\
\text { Nem concordo }\end{array}$ & $\begin{array}{l}\text { 2-Concordo } \\
\text { parcialmente }\end{array}$ & $\begin{array}{l}\text { 1-Concordo } \\
\text { totalmente }\end{array}$ \\
\hline $\begin{array}{l}\text { Realizando o } \\
\text { cadastro do }\end{array}$ & $5,88 \%$ & $4,20 \%$ & $23,53 \%$ & $26,89 \%$ & $39,50 \%$ \\
aplicativo & & & \\
automaticamente & & & \\
começa a gerar & & & \\
descontos, mas \\
mesmo assim está \\
instalado no \\
aparelho celular, \\
para acompanhar as \\
ofertas.
\end{tabular}

\begin{tabular}{|c|c|c|c|c|c|}
\hline $\begin{array}{l}\text { Os produtos } \\
\text { disponíveis em } \\
\text { oferta no aplicativo } \\
\text { são atraentes. }\end{array}$ & $3,33 \%$ & $10,00 \%$ & $17,50 \%$ & $41,67 \%$ & $27,50 \%$ \\
\hline $\begin{array}{l}\text { Quando compro } \\
\text { produtos que estão } \\
\text { em oferta pelo } \\
\text { aplicativo e no final } \\
\text { da compra vejo que } \\
\text { o desconto gerado é } \\
\text { satisfatório. }\end{array}$ & $2,50 \%$ & $5,00 \%$ & $20,00 \%$ & $31,67 \%$ & $40,83 \%$ \\
\hline $\begin{array}{l}\text { O aplicativo é de } \\
\text { fácil acesso e } \\
\text { manuseio, possibilita } \\
\text { verificar as ofertas e } \\
\text { também utilizar as } \\
\text { outras opções } \\
\text { disponíveis. }\end{array}$ & $4,20 \%$ & $9,24 \%$ & $10,92 \%$ & $38,66 \%$ & $36,97 \%$ \\
\hline
\end{tabular}

Fonte: Resultados da pesquisa, 2020.

Os dados apresentados na Tabela 3 mostram que a maioria do público que utiliza o aplicativo de compra Pontual se adaptou facilmente ao software. Assim, conforme o quinto aspecto da questão em análise, quase $75 \%$ estão satisfeitos ou muito satisfeitos em relação ao manuseio do aplicativo. Isso se deve, possivelmente, à facilidade para conferir as ofertas e outras opções disponíveis. Do total, $10,92 \%$ dos respondentes não se posicionaram, 9,24\% discordam parcialmente e 4,20\% discordam totalmente.

Em relação aos descontos gerados no final da compra, 40,83\% concordam totalmente, 31,67\% concordam parcialmente, $20 \%$ não concordam/nem discordam, 5\% discordam parcialmente e 2,5\% discordam totalmente. Quanto à possibilidade de os produtos ofertados pelo aplicativo terem qualidades para atrair os 
clientes, 27,5\% concordam totalmente, 41,67\% concordam parcialmente, 17,5\% não concordam/nem discordam, $10 \%$ discordam parcialmente e $3,33 \%$ discordam totalmente.

Sobre a facilidade para obter descontos e poder acompanhar as ofertas diárias e semanais após instalação do aplicativo e realização do cadastro, 39,50\% dos usuários clientes concordam totalmente, 26,89\% concordam parcialmente, 23,53\% não concordam/nem discordam, 4,20\% discordam parcialmente e 5,88\% discordam totalmente.

Tabela 4 - Fatores relacionados à rede Pontual Supermercados

\begin{tabular}{|c|c|c|c|c|c|}
\hline & $\begin{array}{l}\text { 5-Discordo } \\
\text { totalmente }\end{array}$ & $\begin{array}{l}\text { 4-Discordo } \\
\text { parcialmente }\end{array}$ & $\begin{array}{l}\text { 3-Não } \\
\text { concordo/Nem } \\
\text { discordo }\end{array}$ & $\begin{array}{l}\text { 2-Concordo } \\
\text { parcialmente }\end{array}$ & $\begin{array}{l}\text { 1-Concordo } \\
\text { totalmente }\end{array}$ \\
\hline $\begin{array}{l}\text { Em relação a problemas com } \\
\text { algum produto/ serviço, a } \\
\text { resolução é rápida. }\end{array}$ & $6,67 \%$ & $4,17 \%$ & $18,33 \%$ & $27,50 \%$ & $43,33 \%$ \\
\hline $\begin{array}{l}\text { Na Rede de Supermercados } \\
\text { Pontual é fácil achar os } \\
\text { produtos em ofertas do } \\
\text { aplicativo. }\end{array}$ & $3,33 \%$ & $5,00 \%$ & $16,67 \%$ & $26,67 \%$ & $48,33 \%$ \\
\hline O ambiente é harmonioso. & $2,50 \%$ & $6,67 \%$ & $12,50 \%$ & $32,50 \%$ & $45,83 \%$ \\
\hline $\begin{array}{l}\text { O ambiente é ventilado e } \\
\text { arejado. }\end{array}$ & $1,67 \%$ & $4,17 \%$ & $9,17 \%$ & $36,67 \%$ & $48,33 \%$ \\
\hline
\end{tabular}

Fonte: Resultados da Pesquisa, 2020.

Sobre a rapidez da rede Pontual na resolução de problemas com algum produto/serviço, a Tabela 4 mostra que 43,33\% dos usuários concordam totalmente, 27,50\% concordam parcialmente, 18,33\% não concordam/nem discordam, 4,17\% discordam parcialmente, 6,67\% discordam totalmente. Em relação à facilidade para encontrar os produtos em oferta no aplicativo, 48,33\% concordam totalmente, 26,67\% concordam parcialmente, 16,67\% nem concordam/nem discordam, 5\% discordam parcialmente, 3,33\% discordam totalmente.

Ao avaliarem a afirmação de que o ambiente das lojas da rede Pontual é harmonioso, 45,83\% dos clientes participantes da pesquisa concordam totalmente, 32,5\% concordam parcialmente, 12,5\% não concordam/nem discordam, 6,67\% discordam parcialmente, 2,5\% discordam totalmente. A respeito da assertiva "O ambiente é ventilado e arejado", 48,33\% concordam totalmente, 36,67\% concordam parcialmente, 9,17\% não concordam/nem discordam, 4,17\% discordam parcialmente e 1,67\% discordam totalmente.

A Figura 1 (a seguir) traz os resultados sobre a satisfação dos clientes no tocante ao atendimento da rede Pontual Supermercados. Observa-se que aproximadamente $80 \%$ dos participantes estão muito satisfeitos ou satisfeitos com o atendimento. Outros 13,33\% indiferentes, 3,33\% pouco satisfeitos e 4,17\% extremamente insatisfeitos. Verifica-se, portanto, a necessidade de desenvolver ações para conquistar esses clientes que não se posicionaram ou o fizeram negativamente.

Figura 1 - Percepção dos clientes sobre o atendimento da rede Pontual Supermercados 


\section{De torma geral, quăo satisteito ou insatisteito está com o atendimento da Rede de Supermercados Pontual?}

Responderam: 120 ignoraram: 0

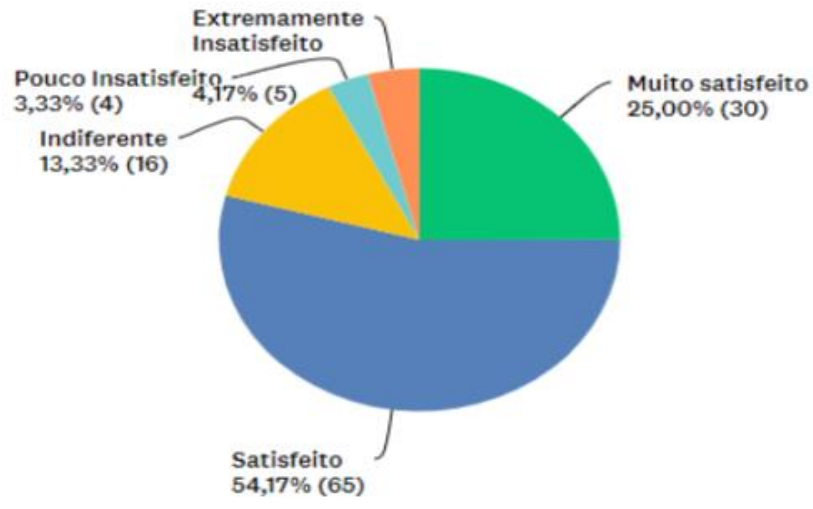

Fonte: Resultados da pesquisa, 2020.

A última questão trata da indicação do aplicativo da rede Pontual Supermercados a outros clientes. Entre os participantes do estudo, 32,50\% afirmaram ser extremamente provável, 38,33\% muito provável, 24,17\% moderadamente provável, 4,17\% pouco provável e 0,83\% nada provável. Os percentuais estão indicados na Figura 2.

Figura 2-Recomendação dos clientes sobre o aplicativo da rede Pontual Supermercados
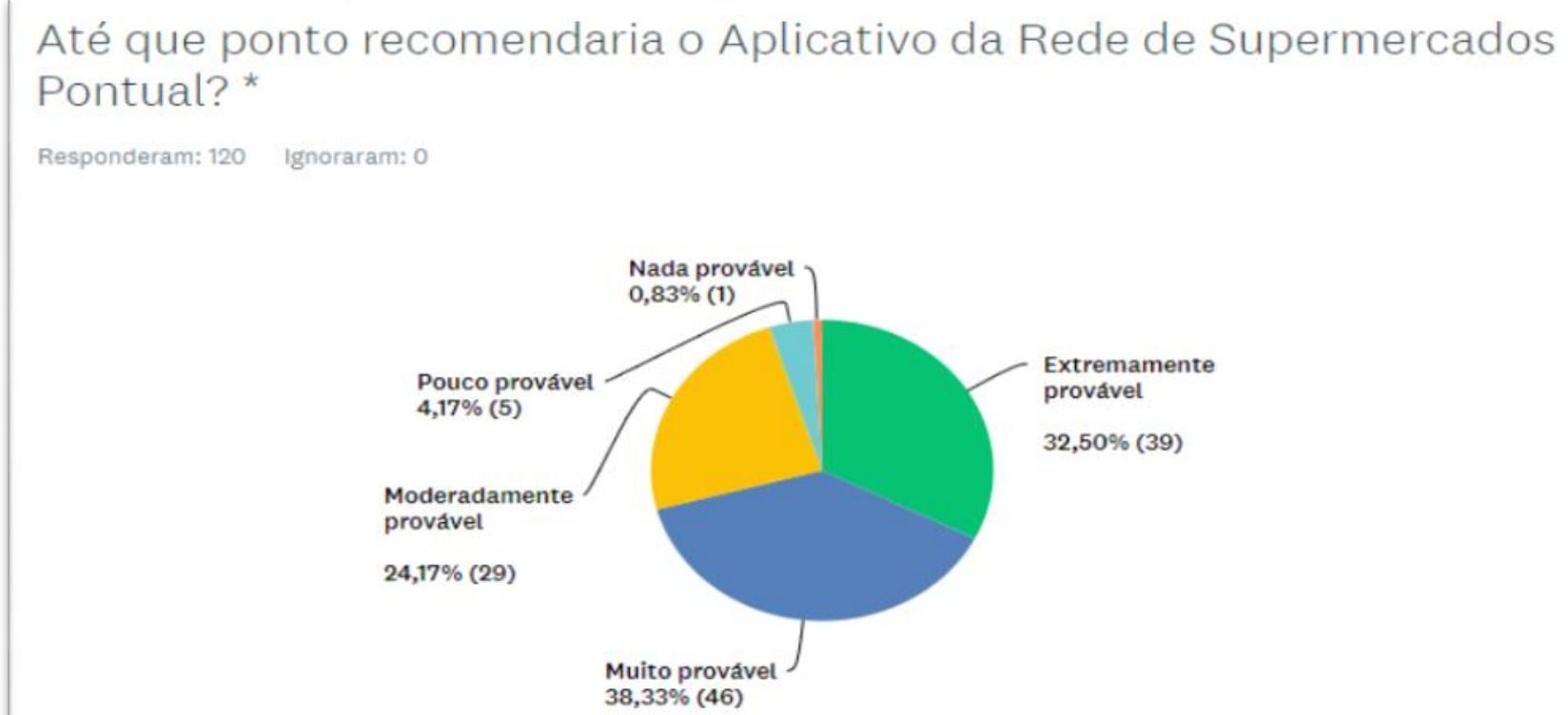

Fonte: Resultados da pesquisa, 2020.

Uma pesquisa denominada "Análise quanto aos processos de qualidade no atendimento aos clientes de uma rede de supermercados na região do Triângulo Mineiro", realizada por Rosa et al. em 2016, com o objetivo de analisar os processos de qualidade para um bom atendimento aos clientes da Pontual Supermercados, verificou que 35,8\% (29) dos entrevistados consideraram ótimo o atendimento do caixa, 60,5\% (49) afirmaram ser bom e 
3,7\% (3), ruim. Essa pesquisa local, associada aos estudos de Alves, (2009) e Gonçalves, (2007), reforça a importância das mudanças organizacionais, particularmente no que tange a elementos como atendimento, fidelização e satisfação de clientes.

Tais resultados vão ao encontro dos verificados na presente pesquisa. Não obstante se tratar de estudos com objetos distintos, é possível constatar que a rede Pontual Supermercados é bem avaliada pela maioria dos pesquisados, quando se trata da percepção coletiva de seus usuários e clientes.

\section{Considerações finais}

O objetivo desta pesquisa foi identificar os principais fatores geradores de satisfação com o uso do aplicativo de compra on-line na prestação de serviços e produtos ofertados pela rede Pontual Supermercados e responder à seguinte questão: quais fatores são determinantes para gerar satisfação de clientes diante do uso do aplicativo desenvolvido pela rede Pontual Supermercados?

Assim, foi realizada pesquisa de campo por meio de aplicação de questionário (survey) entre 120 clientes da rede Pontual Supermercados. Os participantes da pesquisa receberam um link por meio do WhatsApp, com perguntas relacionadas à satisfação dos usuários do aplicativo de compra "Pontual Supermercados Ituiutaba".

Os resultados mostram que o aplicativo é um dos geradores de satisfação dos clientes da rede Pontual Supermercados. Vários fatores contribuem para essa satisfação: notificações exclusivas de ofertas diárias para os clientes do aplicativo; facilidade para ver jornais de ofertas e acompanhar promoções; acúmulo de points que geram "cashback" (dinheiro de volta); descontos em compras e promoções. Desse modo, é possível relacionar a satisfação à fidelização de clientes, já que a maioria dos respondentes avaliou positivamente o aplicativo Pontual.

Sendo assim, os geradores de satisfação que mais se destacaram por meio da percepção coletiva de clientes usuários do aplicativo de compra são: comodidade, rapidez, economia de tempo, promoções, preços e bonificações. Todos eles interferem diretamente no comportamento do consumidor e, consequentemente, na dinâmica de negociação e vendas da rede Pontual Supermercados.

Com base na análise desses fatores, foi possível observar alterações pontuais no nível de satisfação e no comportamento dos clientes analisados, particularmente devido ao preço dos produtos e serviços ofertados pela rede Pontual. Uma sugestão para melhorar essa instabilidade seria desenvolver ações voltadas a elementos que devem orientar preços dos produtos e serviços, visto que a rede Pontual realiza pesquisas de preços dos seus concorrentes semanalmente.

Realizar a pesquisa durante uma pandemia trouxe desafios. Um deles foi a forma de aplicação do questionário, que dificultou a participação de muitos clientes. Outra restrição, a gerência geral da rede Pontual não repassou todas as informações e dados pretendidos no início da pesquisa. Diante disso, foi necessário adaptar o estudo de forma que esses pontos não interferissem nos achados e resultados do trabalho ora realizado.

O tamanho da amostra também constituiu uma importante limitação. Os questionários foram enviados para aproximadamente 450 clientes e publicados nas redes sociais do pesquisador, porém apenas 120 usuários do aplicativo de compra Pontual responderam às questões. 
Conclui-se que a maioria dos clientes pesquisados estão satisfeitos ou muito satisfeitos com o uso do aplicativo de compra on-line da rede Pontual Supermercados. Além dos serviços prestados e de favorecer a adaptação dos clientes às novas tecnologias da informação e comunicação, a localização das lojas da rede Pontual de supermercados (abrangendo cinco grandes e diferentes regiões da cidade) é outra estratégia da rede Pontual com o objetivo explícito de gerar competitividade e atender à população, conforme informou o diretor comercial no decorrer da aplicação do uso da técnica de observação participante.

Uma primeira sugestão para futuras pesquisas são estudos voltados ao neuromarketing, uma área do marketing que tem se desenvolvido bastante e pode estar relacionada aos aplicativos de compra on-line, principalmente quando estes são responsáveis por disparar ofertas e promoções. Outra ideia é a rede implementar um sistema de avaliação de satisfação nas lojas para saber se posicionar diante de determinado resultado e, assim, facilitar e poder contribuir com estudos direcionados ao segmento supermercadista, bem como com uma melhor alocação de investimentos.

\section{Referências}

ABRAS. Associação Brasileira de Supermercados. Análise das $\mathbf{5 0 0}$ maiores. São Paulo: ABRAS, 2019. . Associação Brasileira de Supermercados. Concessão de crédito ao consumidor é o caminho escolhido por muitas redes de supermercados em busca de clientes mais fiéis e comprando mais. São Paulo: ABRAS, 2019. . Associação Brasileira de Supermercados. Ranking 2019: autosserviço. São Paulo: ABRAS, 2019.

ALBERTO, Solange. Fidelização de clientes na distribuição moderna. 2011. Dissertação (Mestrado em Publicidade e Marketing) - Instituto Politécnico de Lisboa, Escola Superior de Comunicação Social, Lisboa, 2011. Disponível em: <https://core.ac.uk/download/pdf/47130954.pdf>. Acesso em: 3 dez. 2019.

ALVES, Danilo Mulatti; GOEDERT, Adriano Rogério. Satisfação dos consumidores em relação ao ponto de venda nos supermercados de Nova Esperança, PR. Revista Cesumar, v. 14, n. 1, 2009, p. 11-33.

BARDIN, Laurence. Análise de conteúdo. Ed. rev. e atual. Lisboa: Edições 70, 2010.

CAMPOS, Vicente Falconi. TQC: controle da qualidade total (no estilo japonês). 2. ed. Belo Horizonte: Editora UFMG, 1992.

GIL, Antônio Carlos. Como elaborar projetos de pesquisa. 4. ed. São Paulo: Atlas, 2007.

GODOY, Arilda Schmidt. Pesquisa qualitativa: tipos fundamentais. Revista de Administração de Empresas. São Paulo, v. 35, n. 3, maio/jun. 2006, p. 20-29.

GONÇALVES, Helmer José. Fidelização de clientes. 2007. Especialização em Administração, Universidade Federal do Rio Grande do Sul, Porto Alegre, 2007. Disponível em: <https://lume.ufrgs.br/handle/10183/14026>. Acesso em: 22 out. 2019.

HAAK, Marianne Kellner. Programa de qualidade e a motivação para o trabalho: um estudo exploratório no setor de serviços. São Paulo: Revista de Administração de Empresa, v. 35, n. 3, 2000, p. 60-70.

LIMA, Marjori Rosa Souto. Satisfação dos consumidores em relação às compras em um supermercado virtual: Um estudo em uma capital de um Estado Brasileiro. 2001. Dissertação (Mestrado em Administração). Universidade Federal do Rio Grande do Sul, Porto Alegre. 
MANGONI, Mari Andréia Luchetta. Elaboração de plano de marketing promocional para empresa FLM Representações Ltda. à luz da Comunicação Integrada de Marketing. 2008. Trabalho de Conclusão (Estágio em Administração) - Universidade do Vale do Itajaí: Itajaí, 2008. Disponível em:

<http://siaibib01.univali.br/pdf/Mari\%20Andreia\%20Luchetta\%20Mangoni.pdf>. Acesso em: 23 nov. 2019.

PMI. Prefeitura Municipal de Ituiutaba. Decreto lei 9.363 de 20 de março de 2020. Contingenciamento no município de Ituiutaba, em virtude da pandemia causada pelo novo coronavírus (Covid-19). Disponível em: https://www.ituiutaba.mg.gov.br/n/noticia/novo-decreto-determina-o-fechamento-de-diversos-setores-docomercio-de-ituiutaba. Acesso em: 21 mar. 2020.

RÉVILION, Anya Sartori Piatnicki. Um estudo sobre a satisfação do consumidor com o setor supermercadista em Porto Alegre. 1998. Dissertação (Mestrado em Administração) Universidade Federal do Rio Grande do Sul, Porto Alegre.

ROESCH, Sylvia Maria Azevedo. Projetos de estágio e de pesquisa em administração: guia para estágios, trabalhos de conclusão, dissertações e estudos de caso. 3. ed. São Paulo: Atlas, 2005.

ROSA, Getúlio; AKEGAWA, Rita de Cássia Dias; MOURA, Marcelino; SANTOS, Marilene. Análise quanto aos processos de qualidade no atendimento aos clientes de uma rede de supermercados na região do triângulo mineiro. Anais do XII congresso nacional de excelência em gestão \& III Inovarse responsabilidade social aplicada, Rio de Janeiro, Setembro, 2016.

SAMARA, Beatriz Santos. Formas de uso e motivações de usuários de celulares da classe c. 2016. 246f. Tese (Doutorado em Ciências Sociais) - Pontífica Universidade Católica de São Paulo, São Paulo, 2016.

SILVA, Jussara Goulart da. O coalinhamento das ações táticas mercadológicas com a expectativa dos consumidores: Caso da rede 20 de supermercados. 2009. Dissertação (Mestrado em Administração) Universidade Federal do Paraná, Curitiba, 2009.

SOUZA, Jéssica Silva; MAGRINI, Maria Angélica de Oliveira. Produção do espaço e consumo: um estudo a partir da atividade supermercadista em Ituiutaba-MG. Geoingá: Revista do Programa de Pós-Graduação em Geografia, v. 9, n. 1, 2017, p. 107-128.

VERGARA, Sylvia Constant. Métodos de pesquisa em administração. 5 ed. São Paulo: Atlas, 2015.

YIN. Robert K. Estudo de caso: planejamento e métodos. 3 ed. Porto Alegre: Bookman, 2005. 